\title{
PHENYLKETONURIA IS NOT A RISK FACTOR FOR CHANGES OF INFLAMMATION STATUS AS ASSESSED BY INTERLEUKIN 6 AND INTERLEUKIN 8 CONCENTRATIONS
}

\author{
Renata Mozrzymas ${ }^{1}$, Monika Duś-Żuchowska², Łukasz Kałużny², \\ Ewa Wenska-Chyży², Jarosław Walkowiak ${ }^{2 \bowtie}$ \\ ${ }^{1}$ Voivodeship Hospital \\ Kamieńskiego 73A, 51-124 Wrocław, Poland \\ 2Department of Pediatric Gastroenterology and Metabolic Diseases, Poznan University of Medical Sciences \\ Szpitalna 27/33, 60-572 Poznań, Poland
}

\begin{abstract}
Background. High oxidative stress and a reduced potential for free radical scavenging in phenylketonuria (PKU) patients, a phenomenon confirmed in a few studies, may lead to systemic chronic inflammation. The aim of this study was to compare the inflammation status, as assessed by interleukin 6 and interleukin 8 concentrations, in patients with PKU and in healthy controls.

Material and methods. Twenty patients with classical PKU, aged 18-34 years and under dietary control, were enrolled in the study. The control group comprised of 20 healthy subjects matched for age and sex. Interleukin 6 and 8 levels were measured by enzyme-linked immunosorbent assay (ELISA) kits in all study participants.

Results. IL-6 concentrations in the study group ranged from $0.74 \mathrm{pg} / \mathrm{ml}$ to $1.34 \mathrm{pg} / \mathrm{ml}$. No significant differences were found between IL- 6 concentration between the study group and the control group $(p=0.989)$. IL-8 concentrations ranged from $17.56 \mathrm{pg} / \mathrm{ml}$ to $20.87 \mathrm{pg} / \mathrm{ml}$. The obtained results of IL-8 levels did not differ significantly between the study group and control group $(p=0.192)$. No significant correlation was observed between Phe blood levels and IL-6 or IL-8 concentrations in the study group ( $\rho$ respectively: $-0.225,0.177$ ). In a multivariate analysis, neither IL- 6 nor IL- 8 concentrations were correlated with sex, age, BMI and Phe levels.

Conclusions. Phenylketonuria is not a risk factor for changes of inflammation status as assessed by IL- 6 and IL-8 concentrations.
\end{abstract}

Key words: phenylketonuria, inflammation, interleukin 6, interleukin 8

\section{INTRODUCTION}

Since Folling's discovery of "imbecillitas phenylpyruvica" in 1934, knowledge of the nature of phenylketonuria (PKU) has broadened. In untreated patients, an accumulation of phenylalanine and its metabolites results in toxic damage of central nervous system due to an impairment of phenylalanine hydroxylase (PAH) activity. Through early diagnosis with neonatal screening, PKU might be effectively treated by a lowphenylalanine diet and/or tetrahydrobiopterin (sapropterin dihydrochloride, $\mathrm{BH} 4$ ) supplementation for PAH 
cofactor responders. The risk for neurocognitive or psychological symptoms in PKU is related to age-ofonset of therapy, lifelong phenylalanine levels, and adherence to treatment (Blau et al., 2010; Folling, 1934; Groselj et al., 2014; Vockley et al., 2014). The literature on early and continuously-treated PKU states that intelligence in patients with optimally treated PKU is comparable to the average population (Moyle et al., 2007; Vockley et al., 2014).

As treatments for the disease become more effective, the children with phenylketonuria age producing a growing population of adults with absent or only mild forms of neurological defects who are then at risk of developing the potential problems specific to the adulthood such as ischemic heart disease, diabetes or cancer. The common denominators linking most of those latter diseases, also known as "Diseases of Civilization" are high oxidative stress (OS) and the inflammatory process (Gonda et al., 2009; Grivennikov et al., 2010; Grivennikov and Karin, 2010; Reuter et al., 2010).

Interleukin 6 (IL-6) and interleukin 8 (IL-8) are well known markers of inflammation. IL-6 is a multifunctional cytokine that plays a role in such areas as the immune response, inflammation, and hematopoiesis. IL-6 exerts pro-inflammatory effects both locally and systemically, which increase the risk of diseases associated with inflammation such as atherosclerosis and coronary heart disease. IL-6 stimulates liver production of acute phase proteins, activates endothelial cells, has pro-coagulant activity, and promotes proliferation and differentiation of lymphocytes (Hartman and Frishman, 2014; Heinrich et al., 1990; Hirano, 2014). IL-8 was the first described angiogenic chemokine. It is considered to be a strong chemokine that promotes angiogenesis, including the creation of new blood vessels in tumor growths (Koch et al., 1992; Rosenkilde and Schwartz, 2004). Both IL-6 and IL-8 play a crucial role in the pathogenesis of sepsis in neonates. They are also known activators of nuclear factor $\kappa B$ (NF-kB) (Spasojević et al., 2012). Proven involvement of the aforementioned substances in the inflammatory process makes them good markers of inflammation in the body.

The aim of the project is to evaluate the concentrations of interleukin 6 and 8 in the population of patients with PKU and to compare it with the control group.

\section{MATERIAL AND METHODS}

\section{Study design}

20 subjects (11 females and 9 males) aged 18-34 years (median value -24.5 years) with classical PKU from the Department of Pediatric Gastroenterology and Metabolic Diseases, Medical University, Poznań and the Voivodeship Hospital, Wrocław, Poland were enrolled in the study. Inclusion criteria were defined as: the diagnosis of classical PKU and an age greater than 10 years. Exclusion criteria were: non-classical forms of PKU (mild PKU, maternal PKU, mild hyperphenylalaninemia, BH4 deficiency) and pregnancy. The control group comprised of 20 healthy subjects matched for age and sex.

Body mass and body height were measured and body mass index (BMI) was calculated in all study patients. Patient compliance status was checked by the last phenylalanine (Phe) level using fluorometric method before study entry. The results are expressed as milligram per deciliter $[\mathrm{mg} / \mathrm{dL}]$. A venous blood sample $(0.5 \mathrm{ml}$ to clot $)$ was collected according to standard methods following an overnight fast. In all study participants, interleukin 6 and 8 levels were measured by enzyme-linked immunosorbent assay (ELISA) kits (eBioscience, Vienna, Austria). The results are reported as picogram per milliliter $[\mathrm{pg} / \mathrm{mL}]$.

\section{Statistical analysis}

Results are presented as means \pm standard deviations (SD) and medians with interquartile ranges. The statistical significance of differences in pro-inflammatory cytokines' levels between patients and controls was determined with the use of Mann-Whitney U test. Rank-sum correlations of Phe blood levels with IL-6 or IL-8 were calculated (Spearman's $\rho$ ). General linear regression models were built, which included age, sex, BMI, Phe concentration, in order to identify risk factors for increased IL- 6 and IL-8 concentrations. The significance level was set at $p<0.05$. Statistical analysis was carried out with STATISTICA 12 software packages (StatSoft Inc., Tulsa, USA). Informed, written consent was obtained from every participant of the study. The study protocol was accepted by the local Bioethics Committee of the Institutional Review Board at Poznan University of Medical Sciences, Poland (approval number 862/14). 
Mozrzymas, R., Duś-Żuchowska, M., Kałużny, Ł., Wenska-Chyży, E., Walkowiak, J. (2016). Phenylketonuria is not a risk factor for changes of inflammation status as assessed by interleukin 6 and interleukin 8 concentrations. Acta Sci. Pol. Technol. Aliment., 15(2), 221-225. DOI: 10.17306/J.AFS.2016.2.22

Table 1. Basic clinical data of studied patients

\begin{tabular}{|c|c|c|c|c|c|}
\hline & \multicolumn{2}{|c|}{ Study group } & \multicolumn{2}{|c|}{ Control group } & \multirow[b]{2}{*}{$p$-value } \\
\hline & $\begin{array}{l}\text { mean } \\
( \pm \mathrm{SD})\end{array}$ & $\begin{array}{c}\text { median } \\
\left(1^{\text {st }} \text { quartile}-3^{\text {rd }} \text { quartile }\right)\end{array}$ & $\begin{array}{l}\text { mean } \\
( \pm \mathrm{SD})\end{array}$ & $\begin{array}{c}\text { median } \\
\left(1^{\text {st }} \text { quartile }-3^{\text {rd }} \text { quartile }\right)\end{array}$ & \\
\hline Age, years & $25.25( \pm 4.55)$ & $24.5(21.5-28.5)$ & $24.22( \pm 3.42)$ & $24.00(22.00-27.00)$ & NS \\
\hline Body weight, kg & $63.25( \pm 10.06)$ & $61.7(55.61-67.56)$ & $63.79( \pm 9.64)$ & $62.00(56.00-71.00)$ & NS \\
\hline Body height, $\mathrm{m}$ & $1.69( \pm 0.07)$ & $1.69(1.64-1.75)$ & $1.71( \pm 0.11)$ & $1.69(1.63-1.77)$ & NS \\
\hline BMI, $\mathrm{kg} / \mathrm{m}^{2}$ & $22.10( \pm 2.72)$ & $21.02(20.26-23.97)$ & $22.15( \pm 1.87)$ & $21.77(20.81-23.20)$ & NS \\
\hline Phe, mg/dL & $9.35( \pm 5.62)$ & $9.06(3.46-14.34)$ & & - & - \\
\hline
\end{tabular}

NS - not statistically significant.

Table 2. Characteristics of IL-6 and IL-8 concentrations

\begin{tabular}{lccccc}
\hline & \multicolumn{2}{c}{ Study group } & \multicolumn{2}{c}{ Control group } & \\
\cline { 2 - 5 } & $\begin{array}{c}\text { mean } \\
( \pm \mathrm{SD})\end{array}$ & $\begin{array}{c}\text { median } \\
\left(1^{\text {st }} \text { quartile-3 } 3^{\text {rd }} \text { quartile }\right)\end{array}$ & $\begin{array}{c}\text { mean } \\
( \pm \mathrm{SD})\end{array}$ & $\begin{array}{c}\text { median } \\
\left(1^{\text {st }} \text { quartile- } 3^{\text {rd }} \text { quartile }\right)\end{array}$ \\
\hline $\mathrm{IL}-6, \mathrm{pg} / \mathrm{ml}$ & 1.072 & 1.035 & 1.174 & 1.06 & 0.989 \\
& $( \pm 0.195)$ & $(0.92-1.24)$ & $( \pm 0.487)$ & $(0.87-1.24)$ & \\
$\mathrm{IL}-8, \mathrm{pg} / \mathrm{ml}$ & 19.12 & 18.77 & 20.68 & 19.66 & 0.192 \\
& $( \pm 0.85)$ & $(18.57-19.71)$ & $( \pm 2.97)$ & $(18.65-21.45)$ & \\
\hline
\end{tabular}

\section{RESULTS}

A description of the anthropological parameters is given in Table 1. IL-6 concentrations in the study group ranged from $0.74 \mathrm{pg} / \mathrm{ml}$ to $1.34 \mathrm{pg} / \mathrm{ml}$. No significant differences were found in the IL-6 concentration between the study group and the control group ( $p=$ 0.989 ). IL-8 concentrations ranged from $17.56 \mathrm{pg} / \mathrm{ml}$ to $20.87 \mathrm{pg} / \mathrm{ml}$. IL-8 levels didn't differ significantly between the study group and control group $(p=0.192$; Table 2).

No significant correlation was observed between Phe blood levels and IL- 6 or IL-8 concentrations in the study group ( $\rho$ respectively: $-0.225 ; 0.177$ ). In a multivariate analysis, no relations between IL-6 nor IL-8 concentrations and sex, age, BMI and Phe levels were found.

\section{DISCUSSION}

The available data suggest a correlation between the inflammatory process and OS. The recruitment of inflammatory cells such as leukocytes and mastocytes during the inflammatory process increases release and accumulation of reactive oxygen species (ROS). ROS modulate various transcription factors including NF$\kappa \mathrm{B}$ and activator protein-1 (AP-1), which regulate the gene-expression of many pro-inflammatory mediators such as cytokines. As a consequence, a sustained inflammatory or oxidative environment leads to a vicious circle (Coussens and Werb, 2002; Reuter et al., 2010).

OS and inflammation are involved in a wide spectrum of diseases; prime examples of which are neurodegenerative diseases (Uttara et al., 2009), cardiovascular disease (Holvoet, 2008), atherosclerosis (Hartman and Frishman, 2014) and cancer (Gonda et al., 2009; Grivennikov et al., 2010; Grivennikov and 
Karin, 2010; Reuter et al., 2010). The linkage between OS and inflammation in neurodegenerative diseases makes the two an interesting target in the population of PKU patients.

A high OS status and a reduced potential of free radical scavenging in PKU patients has been confirmed in a few studies (Rocha and Martins, 2012; Vargas et al., 2011). Sanayama et al. demonstrated that OS status is closely linked with serum phenylalanine levels in PKU patients (Sanayama et al., 2011). Shulpis et al observed that the antioxidant status was lower in patients noncompliant with dietary recommendations (Schulpis et al., 2003).

To the best knowledge of the authors, there was only one study focused on the inflammatory status in PKU patients (Deon et al., 2015). It was focused on a group of patients diagnosed late in the course of the disease. Our study is the first to assess the concentrations of interleukin 6 and 8 in the population of patients with PKU which was diagnosed by neonatal screening.

It is interesting that in our study we observed no significant differences in IL-6 and IL-8 levels between the study and control group. Deon et al observed high lipid and protein oxidative damage, decreased antioxidant defenses, and an increased inflammatory status (IL-6 and IL-1 $\beta$ ) in PKU patients (Deon et al., 2015). The discrepancy between Deon's and our results may result from different characteristics of study group. Deon et al investigated patients diagnosed late with elevated Phe levels at study entrance. In our study, patients were detected by neonatal screening and checked again at study entrance, all the patients were under dietary treatment, and their Phe concentrations were lower than in the aforementioned study. Furthermore, two other limitations of Deon's study group was that it was smaller ( $n=7$ vs $n=20)$ and the time of effective dietary treatment was shorter. It seems Deon's results should be interpreted carefully.

Our findings are in agreement with previous studies in which we assessed inflammatory status of intestinal mucosa detected by fecal calprotectin. No correlation between Phe blood levels and fecal calprotectin concentrations was found in PKU patients (Walkowiak et al., 2013).

\section{CONCLUSIONS}

Phenylketonuria is not a risk factor for changes of inflammation status assessed by IL-6 and IL-8 concentrations.

\section{REFERENCES}

Blau, N., van Spronsen, F. J., Levy, H. L. (2010). Phenylketonuria. Lancet, 376(9750), 1417-1427. Retrieved from http://doi.org/10.1016/S0140-6736(10)60961-0

Coussens, L. M., Werb, Z. (2002). Inflammation and cancer. Nature, 420(6917), 860-867. Retrieved from http://doi. org/10.1038/nature01322

Deon, M., Sitta, A., Faverzani, J. L., Guerreiro, G. B., Donida, B., Marchetti, D. P., ... Vargas, C. R. (2015). Urinary biomarkers of oxidative stress and plasmatic inflammatory profile in phenylketonuric treated patients. International Journal of Developmental Neuroscience: The Official Journal of the International Society for Developmental Neuroscience, 47(Pt B), 259-265. Retrieved from http://doi.org/10.1016/j.ijdevneu.2015.10.001

Folling, A. (1934). Uber Ausscheidung von Phenylbrenztraubensaure in den Harn als Stoff wechselanomalie in Verbindung mit Inbicillitat. Ztschr. Physiol. Chem., 227, 169.

Gonda, T. A., Tu, S., Wang, T. C. (2009). Chronic inflammation, the tumor microenvironment and carcinogenesis. Cell Cycle, 8(13), 2005-2013.

Grivennikov, S. I., Greten, F. R., Karin, M. (2010). Immunity, inflammation, and cancer. Cell, 140(6), 883-899. Retrieved from http://doi.org/10.1016/j.cell.2010.01.025

Grivennikov, S. I., Karin, M. (2010). Inflammation and oncogenesis: a vicious connection. Curr. Opin. Genet. Develop., 20(1), 65-71. Retrieved from http://doi. org/10.1016/j.gde.2009.11.004

Groselj, U., Tansek, M. Z., Battelino, T. (2014). Fifty years of phenylketonuria newborn screening - A great success for many, but what about the rest? Mol. Genet. Metab., 113(1-2), 8-10. Retrieved from http://doi.org/10.1016/j. ymgme.2014.07.019

Hartman, J., Frishman, W. H. (2014). Inflammation and atherosclerosis: a review of the role of interleukin- 6 in the development of atherosclerosis and the potential for targeted drug therapy. Cardiol. Rev., 22(3), 147-151. Retrieved from http://doi.org/10.1097/CRD.000000000000 0021 
Mozrzymas, R., Duś-Żuchowska, M., Kałużny, Ł., Wenska-Chyży, E., Walkowiak, J. (2016). Phenylketonuria is not a risk factor for changes of inflammation status as assessed by interleukin 6 and interleukin 8 concentrations. Acta Sci. Pol. Technol. Aliment., 15(2), 221-225. DOI: 10.17306/J.AFS.2016.2.22

Heinrich, P. C., Castell, J. V., Andus, T. (1990). Interleukin-6 and the acute phase response. Biochem. J., 265(3), $621-636$

Hirano, T. (2014). Revisiting the 1986 molecular cloning of interleukin 6. Front. Immunol., 5, 456. Retrieved from http://doi.org/10.3389/fimmu.2014.00456

Holvoet, P. (2008). Relations between metabolic syndrome, oxidative stress and inflammation and cardiovascular disease. Verhandelingen - Koninklijke Academie Voor Geneeskunde Van België, 70(3), 193-219.

Koch, A. E., Polverini, P. J., Kunkel, S. L., Harlow, L. A., DiPietro, L. A., Elner, V. M., ... Strieter, R. M. (1992). Interleukin-8 as a macrophage-derived mediator of angiogenesis. Science, 258(5089), 1798-1801.

Moyle, J. J., Fox, A. M., Arthur, M., Bynevelt, M., Burnett, J. R. (2007). Meta-analysis of neuropsychological symptoms of adolescents and adults with PKU. Neuropsychol. Rev., 17(2), 91-101. Retrieved from http:// doi.org/10.1007/s11065-007-9021-2

Reuter, S., Gupta, S. C., Chaturvedi, M. M., Aggarwal, B. B. (2010). Oxidative stress, inflammation, and cancer: how are they linked? Free Rad. Biol. Med., 49(11), 1603-1616. Retrieved from http://doi.org/10.1016/j. freeradbiomed.2010.09.006

Rocha, J. C., Martins, M. J. (2012). Oxidative stress in phenylketonuria: future directions. J. Inher. Metab. Dis., 35(3), 381-398. Retrieved from http://doi.org/10.1007/ s10545-011-9417-2

Rosenkilde, M. M., Schwartz, T. W. (2004). The chemokine system - a major regulator of angiogenesis in health and disease. APMIS: Acta Pathol., Microbiol. Immunol. Scand., 112(7-8), 481-495. Retrieved from http://doi. org/10.1111/j.1600-0463.2004.apm11207-0808.x

Sanayama, Y., Nagasaka, H., Takayanagi, M., Ohura, T., Sakamoto, O., Ito, T., ... Okano, Y. (2011). Experimental evidence that phenylalanine is strongly associated to oxidative stress in adolescents and adults with phenylketonuria. Molec. Gen. Metab., 103(3), 220-225. Retrieved from http://doi.org/10.1016/j.ymgme.2011.03.019

Schulpis, K. H., Tsakiris, S., Karikas, G. A., Moukas, M., Behrakis, P. (2003). Effect of diet on plasma total antioxidant status in phenylketonuric patients. Eur. J. Clin. Nutr., 57(2), 383-387. Retrieved from http://doi. org/10.1038/sj.ejcn.1601529

Spasojević, I., Obradović, B., Spasić, S. (2012). Benchto-bedside review: Neonatal sepsis-redox processes in pathogenesis. Critic. Care, 16(3), 221. Retrieved from http://doi.org/10.1186/cc11183

Uttara, B., Singh, A. V., Zamboni, P., Mahajan, R. T. (2009). Oxidative stress and neurodegenerative diseases: a review of upstream and downstream antioxidant therapeutic options. Curr. Neuropharm., 7(1), 65-74. Retrieved from http://doi.org/10.2174/157015909787602823

Vargas, C. R., Wajner, M., Sitta, A. (2011). Oxidative stress in phenylketonuric patients. Mol. Gen. Metab., 104, Suppl., 97-99. Retrieved from http://doi.org/10.1016/j. ymgme.2011.07.010

Vockley, J., Andersson, H. C., Antshel, K. M., Braverman, N. E., Burton, B. K., Frazier, D. M., ... American College of Medical Genetics and Genomics Therapeutics Committee. (2014). Phenylalanine hydroxylase deficiency: diagnosis and management guideline. Genet. Med. 16(2), 188-200. Retrieved from http://doi.org/10.1038/ $\operatorname{gim} .2013 .157$

Walkowiak, J., Cofta, S., Mozrzymas, R., Siwinska-Mrozek, Z., Nowak, J., Kaluzny, L., Banasiewicz, T. (2013). Phenylketonuria is not a risk factor for gut mucosa inflammation: a preliminary observation. Eur. Rev. Med. Pharm. Sci., 17(22), 3056-3059. 